\title{
Non-centrosymmetric Behavior of a Clay Film Ion-exchanged with Chiral Metal Complexes
}

\author{
Yasutaka Suzuki, ${ }^{a}$ Ryoya Matsunaga, ${ }^{a}$ Hisako Sato, ${ }^{b, c}$ Toshihiro Kogure, ${ }^{\mathrm{d}}$ Akihiko Yamagishi ${ }^{\mathrm{e}}$ and Jun \\ Kawamata*a $^{\text {a }}$
}

Received (in XXX, XXX) 1st January 2009, Accepted 1st January 2009

First published on the web 1st January 2009

DOI: 10.1039/b000000x

\begin{abstract}
SHG measurements on a highly transparent clay film ionexchanged with chiral metal complexes revealed that the monomolecular layer of the chiral complexes in an interlayer space acquired a non-centrosymmetric character.
\end{abstract}

A clay is an environmental-friendly ubiquitous substance. Clays have been attracting a continuous interest as a unique host intercalating cationic species at high concentration. ${ }^{1}$ We have been studying the properties of ionexchange adducts of clays and metal complexes with a focus on chiral recognition such as optical resolution, ${ }^{2}$ chiral sensing $^{3}$ and stereoselective energy transfer. ${ }^{4}$

Among clay minerals, a smectite clay is most extensively employed as a host due to its highly expandable character. It is a prevailing view, however, that the intercalation compounds of a smectite clay are difficult to acquire a non-centrosymmetric property because it belongs to a 2:1-type clay, in which each layer has the same phyllosilicate networks on both surfaces. ${ }^{5}$ As a result, polar molecules cancel out their non-centrosymmetry as a whole under the anti-parallel arrangement. One of the counter measures for this is to intercalate two different kinds of molecules in an asymmetric way. In fact, artificial layering based on the Langmuir-Bloodgett technique has been successfully applied to achieve such an arrangement. ${ }^{6}$ In contrast, it is generally impossible to prepare an intercalation compound according to the natural deposition method. ${ }^{7}$

In the present study, we report the preparation of a clay film with non-centrosymmetric character simply by filtering an aqueous suspension of a clay and chiral metal complexes through a membrane filter. The deposited film was transcripted onto a fused silica substrate. We reported that the films obtained under optimized conditions were highly transparent and free from any light scattering. ${ }^{8}$ When the SHG measurements were performed on such a film, an optical second harmonic wave was generated with the dominant contribution of a chiral component of the second-order

${ }^{a}$ Graduate School of Medicine, Yamaguchi University, Yamaguchi, 7538512, Japan.E-mail: j_kawa@yamaguchi-u.ac.jp

${ }^{b}$ Graduate School of Science and Engineering, Ehime University, Matsuyama, 790-8577, Japan.E-mail: hsato@chem.sci.ehime-u.ac.jp c PRESTO, Japan Science and Technology Agency, Chiba, 277-8561, Japan.

${ }^{d}$ Graduate School of Science, The University of Tokyo, Tokyo, 113-0033, Japan.E-mail: kogure@eps.s.u-tokyo.ac.jp

${ }^{e}$ Faculty of Science, Ochanomizu University, Tokyo, 112-8610, Japan. Email yamagishi.akihiko@ocha.ac.jp nonlinear susceptibility, $\chi^{(2)}{ }_{x y z}$. A key to our method was thought to lie in the realization that the clay nanosheet and the monomolecular layer of metal complexes stacked regularly over several micrometers in an alternating way.

The synthesis and resolution of cationic ruthenium(II) complex, $\left[\mathrm{Ru}(\text { phen })_{3}\right] \mathrm{Cl}_{2}$ (phen $=1,10$-phenanthroline), was performed according to the reported method. ${ }^{9}$ The compound was identified by uv-visible and circular dichroism spectra and ${ }^{1} \mathrm{H}$ NMR. The optical purity of the compound was estimated to be higher than $98 \%$ for both enantiomers. Synthetic saponite (Smecton SA, Kunimine Ind. Co. (Japan), Cation Exchange Capacity (CEC): $0.997 \mathrm{meq} \mathrm{g}^{-1}$ ) was used as a clay sample. Homogeneous adsorption was carried out by adding an aqueous solution of the metal complex $(10 \mu \mathrm{M})$ to an aqueous dispersion of a clay (42 $\mathrm{mg} \mathrm{l}^{-1}$ ) dropwis under rigorous stirring. The obtained dispersion was filtered under suction though a membrane filter $\left(4.8 \mathrm{~cm}^{2}\right.$ and $100 \mathrm{~nm}$ pore size) for several hours. The films deposited on the membrane filter were peeled off from the filter. Although self-standing films could be obtained, the film was too thin to mount on optical stage tightly. Therefore, we transferred the film onto a fused silica substrate and then applied for optical measurements. We made thermogravimetric (TG) analysis of the film up to $300 \mathrm{C}$. As a result, monotonic decrease of the weight less than 5\% was observed. Furthermore, absorption spectra were almost identical ever when the film was kept under a low (20\%) and a high (95\%) humidity atmospheres for 72 hours. From these facts, it should be concluded that the film does not include water.

The transparency of the films was ascertained by measuring the absorption spectrum as shown in Figure 1 (a). The absorbance of the films at the wavelength region longer than $660 \mathrm{~nm}$ was nearly zero, where $\left[\mathrm{Ru}(\mathrm{phen})_{3}\right]^{2+}$ absorbed no light. The inset of Figure 1 (a) shows that the absorbance at $450 \mathrm{~nm}$ due to the intercalated metal complex increased linearly with the volume filtered. It implied that the thickness of the film increased uniformly with increase of the deposited amount. In fact, the film thickness as measured by the Swanepoel method $^{10}$ increased linearly with increasing amount of the filtered. The thickness of the film, for example, was $1.6 \mu \mathrm{m}$ when $40 \mathrm{ml}$ of a suspension was filtered.

Figure 1(b) shows the polarized electronic absorption spectra of the film at the filtered amount of $20 \mathrm{ml}$. The absorbance was measured by polarizing the incident light either s- $\left(A_{s}\right)$ or $p-\left(A_{p}\right)$ to the film. The film was rotated at 45 degree with respect to the incident light. The observed 
dichroic ratio $\left(A_{s} / A_{p}\right)$ at $450 \mathrm{~nm}$ was found to be 0.78 . The results were analyzed on the assumption that the transition moment of the metal complex lays uniformly on the plane perpendicular to the $\mathrm{C}_{3}$ molecular axis. As a result, the $\mathrm{C}_{3}$ molecular axis was determined to orient at $\alpha=15$ degree with respect to the normal direction of the film. The clay film intercalating the racemic metal complex gave the same results.

(a)

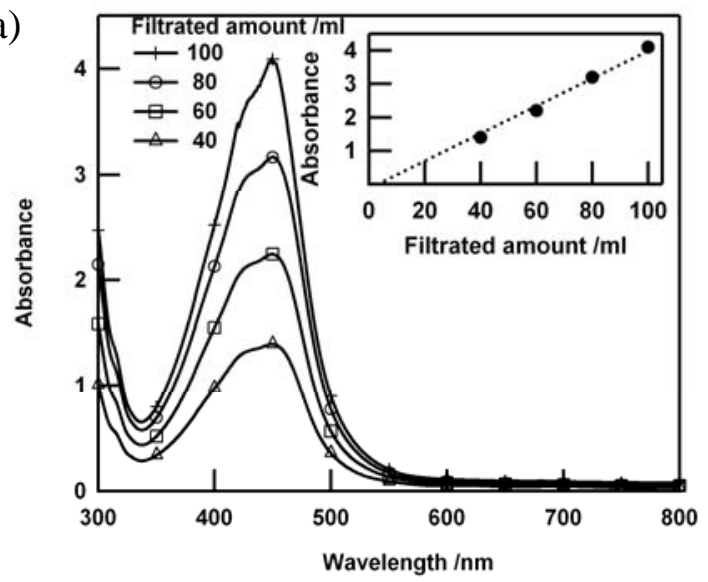

(b)

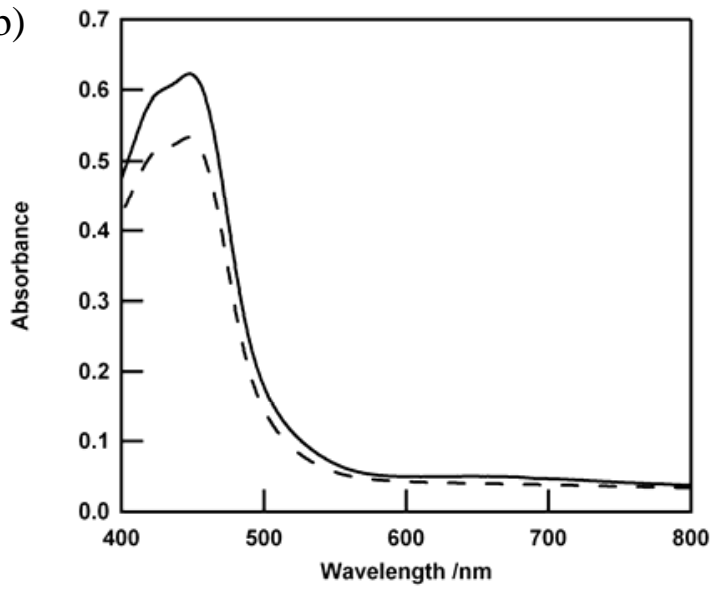

Fig.1 (a) Absorption spectra of the films fabricated by filtrating various amounts $(40 \mathrm{ml}, 60 \mathrm{ml}, 80 \mathrm{ml}, 100 \mathrm{ml})$. The inset is the plot of absorbance at $\lambda_{\max }(450 \mathrm{~nm})$ vs. the filtrated amount: (b) Absorption spectra found with s- (solid line) and p-polarized (dashed line) light for the film at the incident angle of 45 degree.

Figure 2 shows the transmission electron microscopy (TEM) image of the film. The definite layer-by-layer character was confirmed with the interlayer spacing of c.a. 1.8 $\mathrm{nm}$. The electron diffraction pattern indicated the turbostratic layering or there was no preferential orientation of the $a$ - and $b$-axes of clay sheets. The layer-by-layer stacking of clay sheets was observed to extend over a few micrometers. No information was obtained, however, as to the arrangement of the intercalated metal complexes between the clay sheets.

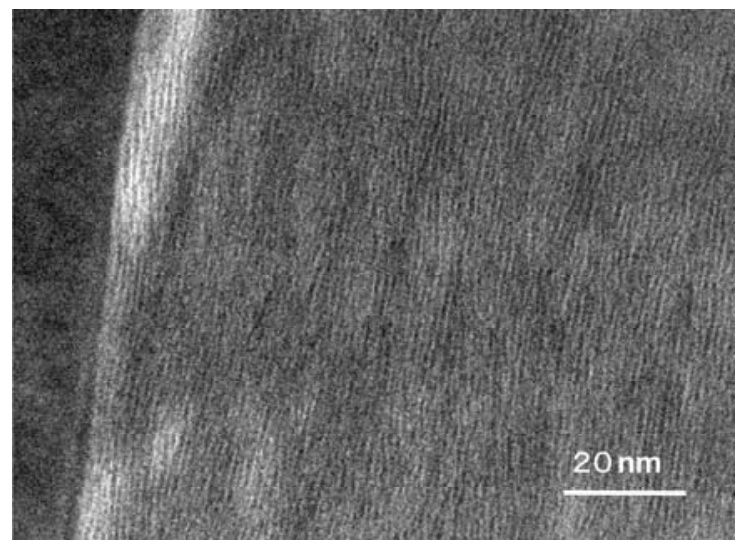

Fig.2 A cross-sectional transmission electron microscopy (TEM) image of the thin clay film. The cross-sectional thin specimen was prepared using a focused ion-beam (FIB) system (Hitachi FB-2100). The TEM observation was performed using a JEOL JEM-2010 UHR.

Figure 3 shows the XRD pattern of the clay thin film, indicating the (001) diffraction at $1.7 \mathrm{~nm}$, which was in accord with the TEM observation. These results implied that the present clay films had a uniform thickness, regular stacking and molecules intercalated in a unique orientation.

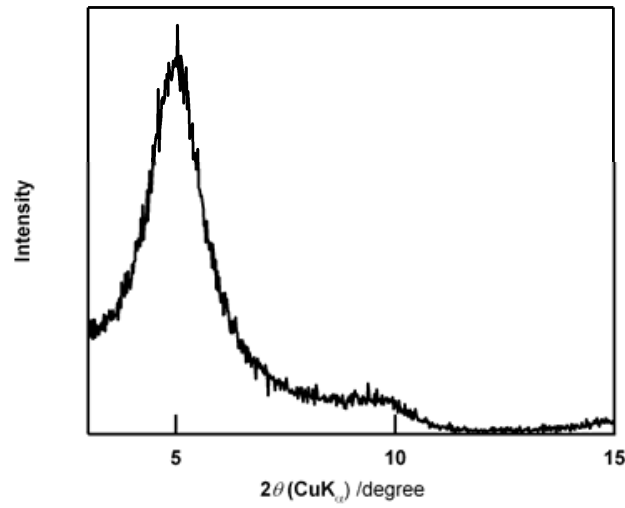

Fig.3 X-ray diffraction patterns for the thin clay film. The peak at $2 \theta(\mathrm{CuK} \alpha)=5.1$ degree was assigned to (001) diffraction.

Figure 4(a) shows the optical second harmonic generation (SHG) signals when reptitively Q-switched pulsed beam from a Nd: YAG laser (Lee 818 TQ) operated at a wavelength of $1064 \mathrm{~nm}$ was irradiated onto a film. Notably the film intercalating chiral metal complexes gave the signal of significant intensity, while the film intercalating racemic metal complexes gave a signal on a negligible level. It should be also emphasized that the SHG signal was observed only $p$-s optical geometries, in which the $p$-polarized fundamental beam was irradiated and the $s$-polarized fundamental beam was detected. The second-harmonic signals were negligible in $p-p, s-p$ and $s-s$ geometry. This fact indicated that the nonvanishing susceptibity component was only $\chi_{x y z}^{(2)}$. The same behavior has been reported for the crystals of chiral materials. ${ }^{11}$ The second-order nonlinear susceptibility $\left(\chi^{(2)}{ }_{x y z}\right)$ was estimated to attain $0.6 \mathrm{pm} \mathrm{V}^{-1}$. ${ }^{12}$

Figure 4(b) shows the dependence of the SHG intensity on the film thickness. When the film thickness was smaller 
than $1 \mu \mathrm{m}$, the signal increased in a quadratic way with respect to the film thickness, while it levelled off at the region thicker than $4 \mu \mathrm{m}$. The behavior of the present film was interpreted in terms of a SHG active three-dimensional crystal with the coherence length ${ }^{13}$ of c.a. $4 \mu \mathrm{m}$. Considering that the typical coherence length of quartz and organic crystals is 20 and $1 \mu \mathrm{m}$, respectively, ${ }^{14,15}$ the estimated value of $4 \mu \mathrm{m}$ as a coherence length seemed to be reasonable since the present film was a hybrid material consisting of alluminosilicates and organic dyes.

(a)

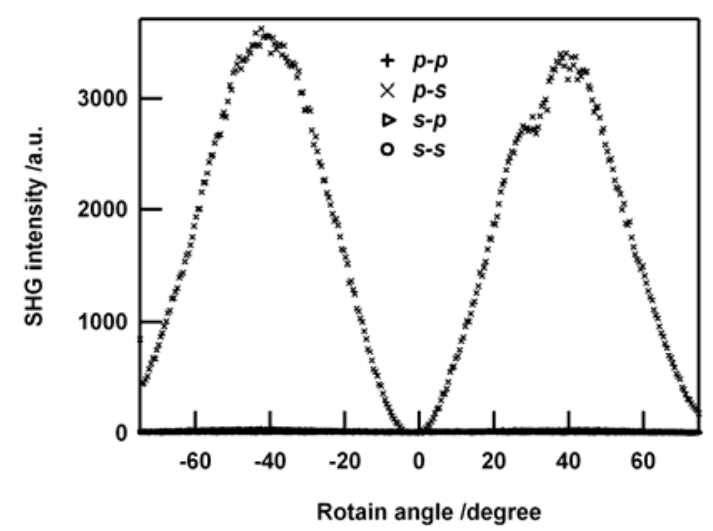

(b)

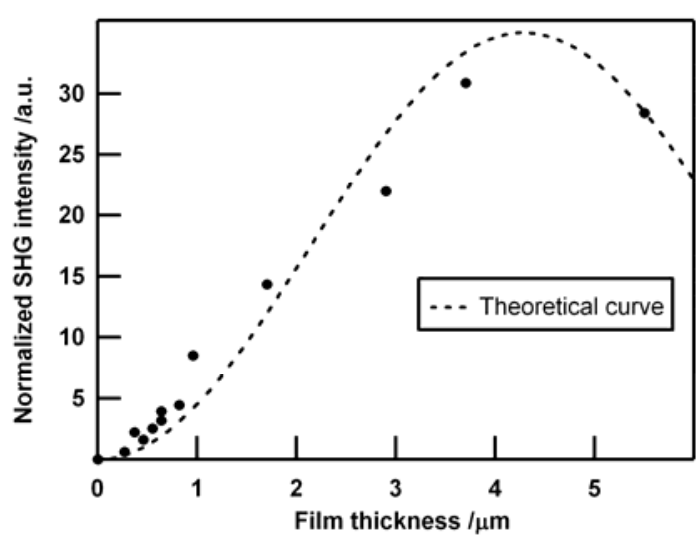

Fig.4 (a) Dependences of the SHG intensity on the incident angle of the laser beam for a film recorded in various optical geometries. The vertical axis is normalized by the SHG intensity of the Maker-Fringe pattern of $d_{11}$ of quartz (wedged sample) recorded at the same experimental conditions. (b) Second-harmonic intensity versus the thickness of the film. The filled circles are the experimental data points and the dashed line a $\sin ^{2}$ fit to the experimental data.
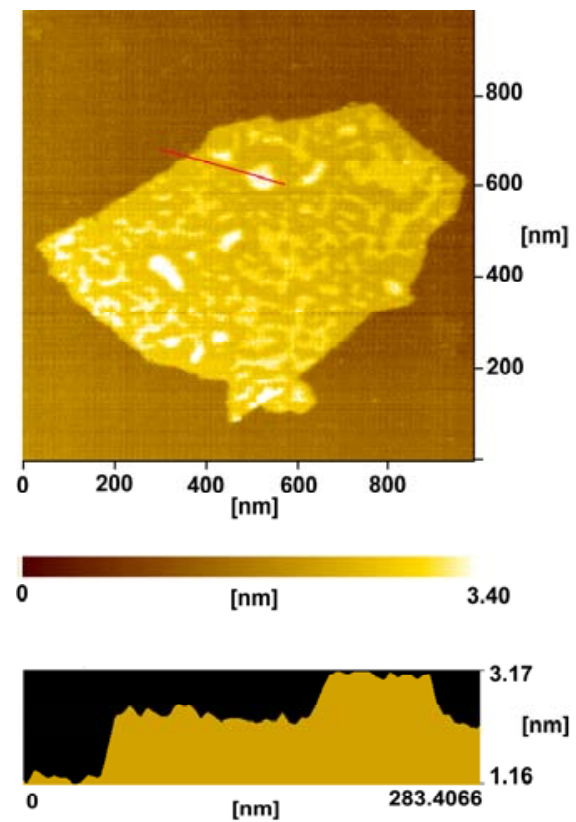

Fig.5 AFM image of the cluster of $\left[\mathrm{Ru}(\mathrm{phen})_{3}\right]^{2+}$ ions adsorbed on a montmorillonite surface.

Figure 5 shows the atomic force microscope (AFM) image of a clay particle adsorbed by $\left[\mathrm{Ru}(\mathrm{phen})_{3}\right]^{2+}$ ions. For the measurements, sodium montmorillonite (Kunipia-P, Kunimine Ind. Co. (Japan), CEC: $1.17 \mathrm{meq}^{-1}$ ) was used instead of the Smecton SA because of its large crystal. We confirmed that the SHG behavior, which is very sensitive to the molecular alignment, of the film employing Kunipia-P was essentially the same as that employing Smecton SA. This fact indicates that the adsorption fashion of $\left[\mathrm{Ru}(\mathrm{phen})_{3}\right]^{2+}$ ions on Kunipia-P were essentially the same with those on Smecton SA, though the CEC of Kunipia-P is little bit larger than that of Smecton SA. Morphology of surface of the present film was typical to those observed for films adsorbing clusters consisting of organic cations adsorbed onto single layer of inorganic nano-sheet. ${ }^{16}$ The height of the cluster was estimated to be c.a. $1 \mathrm{~nm}$. The value was close to the molecular height of $\left[\mathrm{Ru}(\mathrm{phen})_{3}\right]^{2+}$ ion. Thus these ions were concluded to form a cluster with the thickness of a monomolecular layer on a clay crystal surface. The same layer was expected to form within the interlayer space of a clay in the present film. Since such monomolecular layers generated SHG signals exclusively for the chiral case, it was decduced that the chiral molecules in the clusters crystallised in a noncentrosymmetric fashion.

This is a first report of preparing a non-centrosymmetric material based on smectite-type clay minerals by applying the natural deposition method. 


\section{Note and Reference}

1 A. Yamagishi, J. Coord. Chem. 1987, 16, 131-211; S.Takagi, T. Shimada, M. Eguchi, T. Yui, H. Yoshida, D. A. Tryk and H. Inoue, Langmuire, 2002, 18, 2265-2272.

2 A. Yamagishi, J. Phys. Chem., 1982, 86, 2472-2479; A. Yamagishi, K. Naing, Y. Goto, M. Taniguchi and M. Takahashi, J. Chem. Soc., 1994, Dalton Trans., 2085-2089.

3 A. Yamagishi and M. Soma, J. Am. Chem. Soc., 1981, 103, 46404642; Y. Inose, S. Shinobu, A. Aramata, A. Yamagishi and K-. Naing, Chem. Commun., 1997, 111-112; J. X. He, K. Kobayashi, M. Takahashi, G. Villemure and A. Yamagishi, Thin Solid Films, 2001, 397, 255-265.

4 H. Sato, Y. Hiroe, K. Tamura and A. Yamagishi, J. Phys. Chem. B, 2005, 109, 18935-18941.

5 F. Bergaya, B. K. G. Theng and G. Lagaly, Ed. Handbook of Clay Science, Elsevier, Amsterdam, 2006.

6 Y. Umemura, A. Yamagishi, R. Schoonheydt, A. Persoons and F. D. Schryver, J. Am. Chem. Soc., 2002, 124, 992-997; Y. Ogata, J. Kawamata, C. -H. Chong, M. Makihara, A. Yamagishi and G. Saito, Mol. Cryst. Liq. Cryst., 2002, 376, 245-250.

7 R. Takenawa, Y. Komori, S. Hayashi, J. Kawamata and K. Kuroda, Chem. Mater., 2001, 13, 3741-3746.

8 Y. Suzuki, S. Hirakawa, Y. Sakamoto, J. Kawamata, K. Kamada and K. Ohta, Clay. Clay Miner., 2008, 56, 487-493; R. Seike, N. Okawahara, Y. Furukawa, Y. Suzuki, J. Kawamata, K. Kai, Y. Yoshida and G. Saito, Clay Science, 2008, 13, 199-204.

9 J. Kawamata, H. Yamaki, R. Ohshige, R. Seike, S. Tani, Y. Ogata and A. Yamagishi, Coll. Surf. A, 2008, 321, 65-69; S. F. Mason, ed. Molecular chiral Activity and the Chiral Discriminations, Cambridge University Press, Cambridge, 1982.

10 R. J. Swanepoel, J. Phys. E: Sci. Instrum., 1980, 16, 1214-1222.

11 T. Verbiest, S. V. Elshocht, A. Persoons, C. Nuckolls, K. E. Phillips and T. J. Katz, Langmuir, 2001, 17, 4685-4687; S. Sioncke, T. Verbiest and A. Persoons, Mater. Sci. Eng. R, 2003, 42, 115-155.

12 K. Kajikawa, K. Kigata, K. Takekezoe and A. Fukuda, Mol. Cryst. Liq. Cryst., 1990, 182, 91-101; G. J. Ashwell, P. D. Jackson, D. Lochun, P. A. Thompson, W. A. Crossland, G. S. Bahra, C. R. Brown and C. Jasper, Proc. R. Soc. Lond. A, 1994, 445, 385-398.

13 D. A. Kleinman, Phys. Rev., 1962, 128, 1761-1775.

14 J. Jerphagnon, S. K. Kurtz, J. Appl. Phys., 1970, 41, 1667-1681.

15 J. Kawamata, K. Inoue, T. Inabe, Appl. Phys. Lett., 1995, 66, 31023104.

16 K. Akatsuka, Y. Ebina, M. Muramatsu, T. Sato, H. Hester, D. Kumaresan, R. H. Schmehl, T. Sasaki and M. Haga, Langmuir, 2007, 23, 6730-6736. 
We report the SHG characteristics of a clay film intercalating chiral metal complexes. This is the first report of the non-centrosymmetric behavior of smectite-type clay films prepared by natural layering.

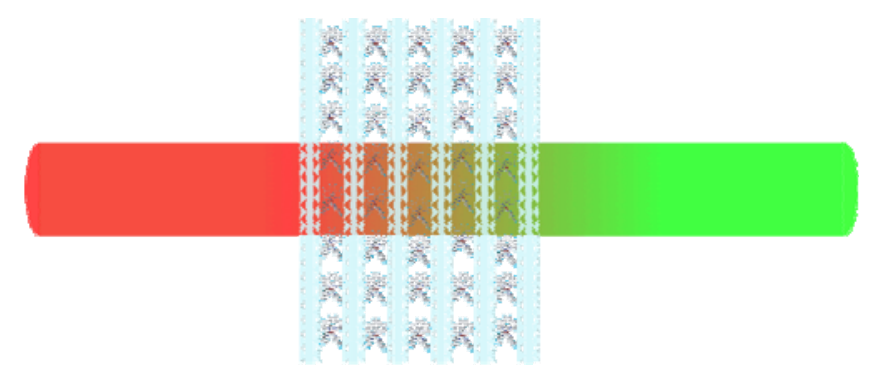

